\title{
界面自组装构筑二维有序介孔聚合物/石墨烯复合材料
}

陈立桅

中国科学院苏州纳米技术与纳米仿生研究所, 江苏苏州 215123

\section{Interfacial Self-Assembled Composite Materials Composed of 2D Polymers with Cylindrical Mesopores on Graphene}

\section{CHEN Liwei}

Suzhou Institute of Nano-Tech and Nano-Bionics, Chinese Academy of Sciences, Suzhou 215123, Jiangsu Province, P. R. China. Email: 1wchen2008@sinano.ac.cn.

Published online: June 18, 2019.
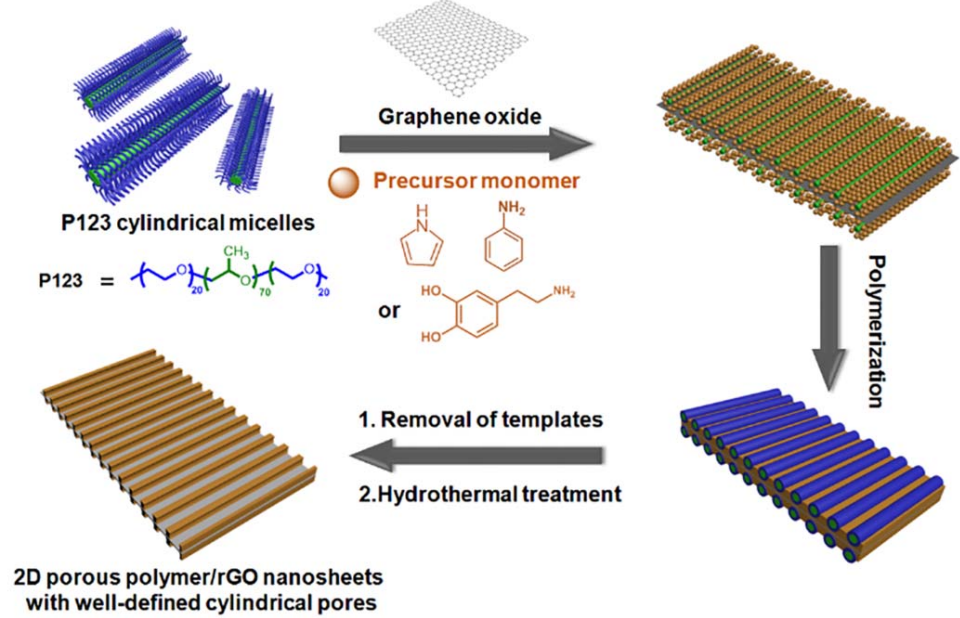

二维有序介孔聚合物/石墨烯纳米片的制备示意图。

自2004年石墨烯发现以来，以其为代表的二 维纳米材料得到了快速发展 1,2 。由于它们具有优 异的电学、光学、力学、热学和化学性能, 有望在 高性能电子器件、能源存储 (如电池、超级电容器) 等领域得到广泛应用 ${ }^{3}$ 。然而, 由于片层间范德华 力的存在, 导致二维纳米片容易堆叠, 比表面积和 活性位点大大降低。而原位生长活性组分于二维 材料表面来制备三明治结构的复合纳米片, 可以抑 制片层的堆叠，并大大提高材料的性能 ${ }^{4}$ 。同时，引 入介孔不仅可以增加材料的比表面积, 缓冲电极 的体积膨胀, 而且能够提高电解液离子的扩散和 器件的电化学性能 5 。因此, 发展二维有序介孔复 合纳米材料能够集成二维材料与介孔材料各自的
优点, 克服它们的缺陷, 将其应用于微型超级电容 器, 可以减小离子传输曲折度, 提高超级电容器的 功率密度; 并且能够增加电荷存储, 提高超级电容 器的能量密度。但是, 目前已有报道的均为面内球 形孔结构的二维介孔纳米材料 ${ }^{6-8}$, 而更有利于电解 质离子传输的具有面内平行柱状孔的有序介孔 纳米片的可控制备仍面临着巨大的挑战。

最近, 上海交通大学麦亦勇教授课题组和中 国科学院大连化学物理研究所吴忠帅研究员课题 组合作, 发展了一种普适的界面自组装策略, 制备 出多种具有面内平行柱状孔的有序介孔聚合物/石 墨烯复合纳米片, 包括聚吡咯/石墨烯、聚苯胺/石 墨烯、聚多巴胺/石墨烯, 并将其应用于全固态平 
面微型超级电容器, 相关结果近期发表在 Angewandte Chemie International Edition 杂志上9 该工作以 $\mathrm{P} 123$ 嵌段共聚物为平行柱状介孔模板 剂, 氧化石墨烯(graphene oxide)为二维基底, 利用 它们之间的氢键作用力, 成功制得多种有序介孔 聚合物/石墨烯复合纳米片。这些纳米片具有面内 平行柱状的有序介孔, 大小为 $11-12 \mathrm{~nm}$, 厚度为 25-27 nm, 同时结合了高电化学活性的噟电容聚 合物和高导电性的双电层石墨烯的优势。获得的 微型超级电容器表现出高体积比容量和能量密 度, 同时具有优异的机械柔性和串并联集成性能。

此项工作为可控制备二维有序介孔复合材料 提供了新思路, 为设计组装高比能储能材料和器 件提供了新策略。

\section{References}

(1) Geim, A. K. Science 2009, 324, 1530. doi: 10.1126/science. 1158877

(2) Deng, D. H.; Novoselov, K. S.; Fu, Q.; Zheng, N. F.; Tian, Z. Q.; Bao, X. H. Nat. Nanotech. 2016, 11, 218. doi: 10.1038/nnano.2015.340
(3) Wu, Z. S.; Feng, X. L.; Cheng, H. M. Natl. Sci. Rev. 2014, 1, 277. doi: $10.1093 / \mathrm{nsr} / \mathrm{nwt} 003$

(4) Tian, H.; Zhu, S. Y.; Xu, F. G.; Mao, W. T.; Wei, H.; Mai, Y. Y.; Feng, X. L. ACS Appl. Mater. Interfaces 2017, 9, 43975. doi: $10.1021 /$ acsami.7b13666

(5) Qin, J. Q.; Wang, S.; Zhou, F.; Das, P.; Zheng, S.; Sun, C.; Bao, X. H.; Wu, Z. S. Energy Storage Mater. 2019, 18, 397. doi: 10.1016/j.ensm.2018.12.022

(6) Liu, S. H.; Gordiichuk, P.; Wu, Z. S.; Liu, Z. Y.; Wei, W.; Wagner, M.; Mohamed-Noriega, N.; Wu, D. Q.; Mai, Y. Y.; Herrmann, A.; et al. Nat. Commun. 2015, 6, 8817. doi: 10.1038/ncomms 9817

(7) Zhu, S. Y.; Tian, H.; Wang, N.; Chen, B.; Mai, Y. Y.; Feng, X. L. Small 2018, 14, 1702755. doi: 10.1002/smll.201702755

(8) Hou, D.; Zhu, S. Y.; Tian, H.; Wei, H.; Feng, X. L.; Mai, Y. Y. ACS Appl. Mater. Interfaces 2018, 10, 40800. doi: 10.1021/acsami.8b15250

(9) Tian, H.; Qin, J.; Hou, D.; Li, Q.; Li, C.; Wu, Z. S.; Mai, Y. Y. Angew. Chem. Int. Ed. 2019, 58, 10173. doi: 10.1002/anie.201903684 